\title{
CEFALÉIAS PRIMÁRIAS: ASPECTOS CLÍNICOS E TERAPÊUTICOS
}

\author{
PRIMARY HEADACHES: CLINICAL AND THERAPEUTIC ASPECTS
}

Wilson Luiz Sanvito ${ }^{1} \&$ Paulo Hélio Monzillo ${ }^{2}$

${ }^{1}$ Professor Titular de Neurologia; ${ }^{2}$ Professor Visitante - Faculdade de Ciências Médicas da Santa Casa de São Paulo CorResPondênCIA: Faculdade de Ciencias Médicas da Santa Casa de São Paulo - Rua Doutor Césario Motta Júnior $n^{\circ} 176-8^{\circ}$ andar CEP: 01221-020 - São Paulo - SP.

SANVITO WL \& MONZILLO PH. Cefaléias primárias: aspectos clínicos e terapêuticos. Medicina, Ribeirão Preto, 30: 437-448, out./dez. 1997

RESUMO: Nesta revisão, as cefaléias primárias são conceituadas como doenças crônicas, de apresentação episódica ou contínua, com etiologia desconhecida, mas de natureza disfuncional, não estrutural. As quatro principais formas de cefaléia primária (enxaqueca, cefaléia em salvas, tensional e crônica diária) são discutidas em seus aspectos etiopatogênicos, clínicos e terapêuticos.

UNITERMOS: Cefaléia. Terapêutica.

\section{INTRODUÇÃO}

A dor de cabeça é uma das queixas mais freqüentes na prática médica do dia-a-dia. As suas determinantes etiológicas podem se dever a patologias estruturais nervosas ou extra-nervosas (processos expansivos intracranianos, meningoencefalites, sinusopatias), sistêmicas (estados infecciosos, lúpus eritematoso sistêmico) ou a quadros disfuncionais (enxaquecas, cefaléias tipo tensional).

A queixa de cefaléia, com certa freqüência, constitui um desafio para o médico, em virtude da diversidade dos tipos de cefaléia encontrados. Às vezes, a abordagem do paciente deve ser multidisciplinar. Existem hoje, bem definidos, mais de 100 tipos de cefaléia.

O conceito de cefaléia primária é ainda impreciso, mas, com finalidades didáticas, pode-se adotar o conceito que se segue: "Trata-se de cefaléia crônica, de apresentação episódica ou contínua e de natureza disfuncional, o que significa a não participação de processos estruturais na etiologia da dor". Paradoxalmente, o que nos permite reunir tais tipos de cefaléia, num mesmo capítulo, é o desconhecimento de sua etiopa- togenia. Com um critério prático e meramente descritivo, vamos abordar as seguintes formas de cefaléia primária: enxaquecas, cefaléia em salvas, cefaléia tipo tensional e cefaléia crônica diária.

\section{ENXAQUECAS}

Vamos começar com o conceito de enxaqueca (EXQ). Trata-se de uma reação neurovascular, anormal, num organismo geneticamente vulnerável, que se exterioriza, clinicamente, por episódios recorrentes de cefaléia e manifestações associadas e que, geralmente, dependem da presença de fatores desencadeantes. Esta definição, embora singela, tem a vantagem de incorporar os dois fatores fundamentais da EXQ: o endógeno e o exógeno, e a conjugação de fatores endógenos (genéticos) e exógenos (ambientais) é fundamental para a deflagração da crise.

A EXQ tem início, geralmente, na infância, na adolescência ou nos primórdios da idade adulta, e é mais freqüente no sexo feminino, na proporção de 3:1. Sua freqüência é bastante alta e se estima que $12 \%$ da população sofra de EXQ. 
A EXQ tem sido reconhecida desde o início da civilização. Embora haja relato de EXQ com escotomas, em crônicas sumerianas, desde há 3000 anos, a descrição pormenorizada deste tipo de cefaléia nos foi proporcionada por Areteu da Capadócia (atual Turquia Asiática) quase no fim do primeiro século de nossa era (81 D.C.). Este autor usou a expressão "hemicrania", que permanece até nossos dias. Para outros, foi Galeno quem utilizou pela primeira vez a palavra "hemicrania", 200 anos depois de Cristo. Embora a datação da EXQ seja da era sumeriana, o desenvolvimento de seu estudo integrado e com bases científicas começa com Wolff e sua escola, na década de 30, nos Estados Unidos.

No conceito de EXQ foi valorizada a presença de fatores endógenos (genéticos) e fatores exógenos (ambientais). A caracterização genética ainda é imprecisa, embora esse fator seja inquestionável. É muito provável que a herança seja do tipo multifatorial. Embora os aspectos genéticos da EXQ sejam ainda pobremente compreendidos, pelo menos na enxaqueca hemiplégica familiar, já foram identificadas mutações no cromossomo 19. No que tange aos fatores ambientais, eles atuam como desencadeantes de uma crise. Entre os principais fatores desencadeantes podem ser arrolados: problemas emocionais (ansiedade ou depressão), modificação do ciclo vigília-sono (excesso ou privação do sono), ingestão de bebidas alcoólicas (particularmente de vinho tinto), ingestão de determinados alimentos (chocolate, certos tipos de queijos defumados), jejum prolongado, exposição a odores fortes e penetrantes ou a estímulos luminosos intensos e/ou intermitentes.

A EXQ, como mostra a Tabela I, apresenta vários subtipos, com critérios diagnósticos definidos pela International Headache Society (IHS). Vamos analisar os dois primeiros, em virtude de sua frequiência na população.

A EXQ sem aura é a mais freqüente na prática clínica e representa aproximadamente $80 \%$ das formas de EXQ. Pode ser definida como dor de cabeça idiopática, recorrente, manifestando-se por crises com duração de 4-72 horas. Do ponto de vista clínico, a dor costuma apresentar localização unilateral, qualidade pulsátil, intensidade moderada ou acentuada, sendo exacerbada pelas atividades físicas de rotina e, habitualmente, fazem parte da crise náuseas e/ou vômitos, foto e fonofobia. A caracterização da crise enxaquecosa exige a presença de pelo menos duas (ou mais) das características da dor, que deve ser acompanhada de, pelo menos, uma das manifestações associadas (náuseas, vômitos, foto, fonofobia). O diagnóstico de EXQ exige que o paciente tenha, no mínimo, cinco crises que preencham os critérios considerados.

A EXQ com aura é menos freqüente e representa aproximadamente 10 a $15 \%$ das formas clínicas de EXQ. Este tipo de EXQ é caracterizado pela presença de aura, que se exterioriza por manifestações neurológicas reversíveis que, por sua vez, sinalizam comprometimento do córtex cerebral ou do tronco encefálico. Foi estabelecido o tempo mínimo de quatro minutos para a duração da aura como forma de diferenciá-la dos sintomas semelhantes observados durante um ataque isquêmico transitório, que são habitualmente mais fugazes. A duração habitual da aura é de cinco a vinte minutos, mas pode chegar até a sessenta minutos. Excepcionalmente, a aura é prolongada, com duração superior a sessenta minutos. A crise enxaquecosa, habitualmente, começa com a aura, e a fase álgica se instala nos minutos subseqüentes, geralmente quinze a vinte minutos após o início da aura, podendo este intervalo ser maior, observando-se um período máximo de sessenta minutos. Em alguns casos, a dor de cabeça pode preceder a aura ou ter início juntamente

Tabela I - Formas clínicas de enxaqueca*

ENXAQUECA

- Enxaqueca sem aura.

- Enxaqueca com aura.

- Enxaqueca com aura típica.

- Enxaqueca com aura prolongada.

- Enxaqueca hemiplégica familiar.

- Enxaqueca basilar.

- Enxaqueca com aura sem cefaléia.

- Enxaqueca com instalação súbita.

- Enxaqueca oftalmoplégica.

- Enxaqueca retiniana.

- Síndromes periódicas da infância que podem ser precursoras de ou associadas com enxaqueca.

- Vertigem paroxística benigna da infância.

- Hemiplegia alternante da infância.

- Complicações da enxaqueca.

- Estado enxaquecoso.

- Infarto enxaquecoso.

- Desordem enxaquecosa, não preenchendo os critérios anteriores

*Segundo a International Headache Society 
com ela. Para se firmar o diagnóstico de EXQ com aura é preciso que o paciente apresente, pelo menos, duas crises que preencham os critérios diagnósticos. A duração da fase álgica deste tipo de EXQ, geralmente, é mais curta do que a da EXQ sem aura e costuma durar de quatro a seis horas, podendo, entretanto, ser prolongada e atingir até setenta e duas horas. Às vezes, a crise se resume à aura, com ausência da fase álgica. É a chamada enxaqueca sine enxaqueca.

Manifestações clínicas - Alguns enxaquecosos apresentam manifestações prodrômicas, que precedem a crise propriamente dita em várias horas ou até por período superior a vinte e quatro horas. Estas manifestações incluem: distúrbios do humor (irritabilidade, ansiedade, euforia, depressão), distúrbios do sono (bocejos freqüentes, sonolência, insônia), distúrbios intelectivos (embotamento mental, diminuição da concentração, aumento da acuidade mental), distúrbios gastrointestinais (inapetência, bulimia, dispepsia, obstipação).

A crise da EXQ sem aura tem início com dor de cabeça holocraniana ou hemicraniana, de tipo contínuo, com intensidade baixa ou moderada e que vai se exacerbando nas horas subseqüentes. No período de estado da crise, a dor é de grande intensidade, assume o caráter latejante, e costuma ser acompanhada de fotofobia, fonofobia, osmofobia e náusea. Nessa fase, a dor é exacerbada por esforços físicos e a tendência do paciente é procurar um ambiente silencioso e escuro. $\mathrm{O}$ exame do paciente pode evidenciar, nas formas hemicrânicas, um aumento na pulsatibilidade da artéria temporal superficial, que se torna visível, do mesmo lado da dor, fato que pode ser observado à simples inspeção do paciente. Em algumas crises, certos enxaquecosos podem apresentar vômitos, no final da fase álgica.

As manifestações neurológicas da EXQ podem preceder o quadro álgico, acompanhá-lo ou, até mesmo, permanecer após a sua resolução. É a chamada EXQ com aura, e esta pode se traduzir por manifestações visuais, sensitivas, motoras e afásicas. A aura mais encontradiça nos enxaquecosos é a visual, que ocorre em mais da metade desta forma de EXQ. A duração, geralmente, é fugaz, indo de alguns minutos a até uma hora. As alterações visuais podem se traduzir por escotomas, quadrantanopsias ou hemianopsias. As amauroses transitórias são menos freqüentes. Os escotomas podem ser negativos, com falta de visão num determinado ponto do campo visual. Já, os escotomas positivos podem assumir diferentes formas: escotomas cin- tilantes, moscas volantes, espectros de fortificação, ilusão de luzes oscilantes ou sensação de flashes de luz (fosfenos) ou traçados em ziguezague. Alguns pacientes se queixam de borramento visual (visão pouco nítida), com a sensação de olhar através da água ou de uma nuvem de vapor. Os escotomas podem aumentar de tamanho, no desenrolar da crise, ou fragmentar-se em partes menores. Os espectros de fortificação são experimentados por cerca de $10 \%$ dos pacientes e a denominação deste tipo de escotoma encontra justificativa na aparência de ziguezague da alucinação visual, que se assemelha à figura de uma cidade-fortaleza vista de cima (a comparação é com um forte apache). Esta forma de escotoma também é conhecida como teicopsia, expressão derivada do grego teichos cujo significado é parede.

Gowers, em 1892, foi um dos primeiros a descrever os escotomas na fase pré-álgica da EXQ Lashley, em 1941, descreveu pormenorizadamente seus próprios escotomas e chegou a calcular, do ponto de vista temporal, sua perda visual em muitas ocasiões, e concluiu que a extensão de seu distúrbio visual progredia com a velocidade de $3 \mathrm{~mm}$ por minuto. Neste ponto, deve ser ressaltado que o fenômeno descrito como depressão alastrante (spreading depression) no córtex cerebral, pelo neurofisiologista brasileiro Leão, progride com a mesma velocidade. Esta é uma das teorias postuladas, hoje, para explicar os sinais e sintomas neurológicos focais, correspondentes à aura da EXQ.

Embora os escotomas possam variar na sua forma, geralmente são constituídos por alucinações elementares (flashes de luz, bolas coloridas, linhas em ziguezague, cintilações, por exemplo), sendo excepcional o aparecimento de imagens visuais de formação mais elaborada. Tal fato encontra explicação no envolvimento mais freqüente do lobo occipital na crise enxaquecosa, e a disfunção de certas áreas deste lobo pode se traduzir por alucinações visuais elementares. Também alucinações visuais elaboradas, sob a forma de figuras humanas ou de animais, têm sido descritas, sugerindo um envolvimento do córtex têmporoparietal. Finalmente, no escotoma astenótipo, o paciente enxerga as figuras animadas ou objetos cortados ao meio.

Outras formas de comprometimento do campo visual podem configurar uma quadrantanopsia (déficit num quadrante do campo) ou uma hemianopsia (déficit numa metade do campo). O déficit do campo visual pode progredir de maneira gradual ou afetar, ab initio, ambas as metades da visão. 
Outros tipos de aura, como as sensitivas e psíquicas, podem ocorrer de modo isolado ou associadas à aura visual. O comprometimento sensitivo unilateral é uma queixa relativamente freqüente no início da crise. Os distúrbios sensitivos, geralmente, adotam a forma de adormecimento ou formigamento (parestesias) nas extremidades distais dos membros ou na face. Freqüentemente, assumem uma distribuição unilateral (localizando-se num segmento corporal ou num hemicorpo). Com certa frequiência, o distúrbio sensitivo pode ocorrer sob a forma de parestesia quiro-oral (mão-boca), associada ou não a escotomas.

Certos enxaquecosos apresentam distúrbios sensitivos mais complexos ou elaborados, denunciando envolvimento de áreas têmporoparietais (alterações psicossensoriais). Nesses casos são comuns alterações do esquema corporal, descrevendo, os pacientes, percepções distorcidas de sua imagem corporal: sensação de membros enormes ou de um segmento corporal deformado. Lewis Carroll, que sofria de enxaqueca, descreve, de modo magnífico, essas sensações, no seu famoso conto "Alice no País das Maravilhas". Entretanto, vem sendo questionado, ultimamente, se as descrições de Carroll estão calcadas na sua vivência de enxaquecoso, pois, sabe-se agora, que "Alice" foi redigido antes de o autor começar a sofrer de enxaqueca.

Também alucinações olfatórias, idênticas às observadas nas crises epilépticas ditas uncinadas, assim como manifestações assemelhadas à epilepsia do lobo temporal (dejá vu, jamais vu) têm sido relatadas como auras enxaquecosas. O diagnóstico diferencial, com epilepsia focal, nessa eventualidade, é difícil; entretanto alguns critérios podem auxiliar, como o aparecimento de cefaléia do tipo enxaquecoso ou a instalação de crise do tipo Grande Mal após a aura. Por outro lado, o desenvolvimento da aura enxaquecosa costuma ser mais lento do que o da epiléptica. Não nos esqueçamos de que a associação entre epilepsia e enxaqueca, comprovadamente, não é fortuita, o que nos deve deixar atentos, tratando-se de pacientes com os quais ocorra concomitância ou dificuldade de interpretação dos sintomas.

Outras manifestações neurológicas podem ocorrer na fase pré-álgica, álgica ou pós-álgica: hemiparesia, afasia, vertigem, diplopia.

\subsection{Tratamento da enxaqueca}

Procuraremos traçar estratégias para o tratamento do enxaquecoso e não da enxaqueca, o que significa que vamos inverter o enfoque, procurando tratar o paciente e não a doença. Embora o uso de fármacos seja o prato de resistência do tratamento do enxaquecoso, é preciso considerar que este é um ser inserido em seu meio ambiente e que reage aos mais diversos estímulos (biológicos, psicológicos, sociais, culturais) de maneira anômala, o que pode gerar, em seu organismo, geneticamente vulnerável, uma crise. Neste sentido, nós temos que desdobrar o tratamento do enxaquecoso em dois itens: 1) medidas gerais; 2) medidas farmacológicas. (Tabela II).

\section{Tabela II - Tratamento da enxaqueca}

MEDIDAS GERAIS ( $p /$ casos leves)

- Compressão das artérias temporais

- Aplicação de gelo ou spray gelado na têmpora

- Escalda-pés quente, mais toalha fria na cabeça

- Banho de contraste (quente - frio)

- Técnicas de bio-feedback

- Inalação de $\mathrm{O}_{2}$ puro (5-7 L/min por 15 - 20 min.)

- Respiração em saco plástico (por 5 - 8 min.) ou de carbogênio

- Indução de sono não medicamentoso (crianças)

TRATAMENTO MEDICAMENTOSO

1. Crise aguda

- Análgesico não narcótico

- Antiinflamatório não esteroidal, mais antiemético

- Derivados ergóticos

- Isometepteno

- Sumatriptan

2. Estudo de mal enxaquecoso

- Corticosteróides: Dexametasona 16 mg/dia ou Metilprednisolona $80 \mathrm{mg} / \mathrm{d}$ mais antiemético

- Clorpromazina 0,7 mg//kg (mais $50 \mathrm{mg}$ ) EV diluída em 250 ml SF em $1 \mathrm{~h}$

- Diidroergotamina EV: não disponível no Brasil

3. Tratamento profilático

- Bloqueadores dos canais de cálcio: Flunarizina $5-10 \mathrm{mg} / \mathrm{d}$

- Betabloqueadores: Propanolol 40-160 mg/d ou Atenolol (50-100 mg/d)

- Antidepressivos: Amitriptilina 50-150 mg/d

- Derivados do ergot: Maleato de Metisergida 3-6 mg/d ou Pizotifeno (2-4 mg/d)

- Valproato de Sódio: 1200 mg/d

- Naproxen Sódico: 1000 mg/d nos dias - 5 a + 2 da menstruação 
Nas medidas gerais, é preciso considerar a abordagem do paciente na primeira consulta, levando em conta o seu perfil psicológico e os hábitos de vida, os fatores desencadeantes da crise e a adoção de medidas terapêuticas não farmacológicas (relaxamento muscular, acupuntura, massagens, do-in, psicoterapia, bio-feedback), já utilizadas ou não. Por outro lado, é preciso considerar ainda que o tratamento pode ser desdobrado em sintomático (tratamento da crise) e profilático (tratamento preventivo ou de manutenção).

Como podemos interromper uma crise de EXQ? Se a crise não for de grande intensidade, a simples compressão da artéria temporal, na têmpora, proporciona, muitas vezes, alívio. Do mesmo modo, uma venda apertada na cabeça ajuda no alívio da dor. Alguns enxaquecosos preferem a aplicação de uma bolsa de gelo na têmpora ou a aplicação de um spray gelado nessa região. Outro procedimento usado pelos pacientes é um escalda-pés em água bem quente, associado à aplicação de uma toalha fria na cabeça. $\mathrm{O}$ banho de contraste pode ser útil: um banho quente seguido de um frio. Também técnicas de bio-feedback podem ser úteis para alguns pacientes, com o objetivo de desviar excesso de sangue do segmento cefálico para outros segmentos corpóreos. Em certas circunstâncias, quando o uso de fármacos está contra-indicado, na gestante, por exemplo, pode-se lançar mão da inalação de oxigênio puro (cinco a sete litros por minuto durante quinze a vinte minutos). Nos casos de aura prolongada, pode-se tentar a respiração durante cinco a oito minutos, num saco plástico ou a inalação de carbogênio. Na criança, o melhor tratamento para a crise é a indução do sono não medicamentoso. Enfim, estes recursos poderão ser acionados, mas, seguramente, são inúteis nas crises de grande intensidade, prolongadas ou de recorrência muito freqüente. Nestes casos, o uso de fármacos se impõe.

Os critérios para o tratamento da fase crítica da EXQ dependem de uma série de fatores: 1) tipo de EXQ; 2) intensidade da crise; 3) duração da crise; 4) presença de manifestações associadas à dor, particularmente mal-estar com náuseas, vômitos, tontura; 5) presença de aura prolongada; 6) condições físicas e psicológicas do paciente; 7) idade do paciente, levando em conta, principalmente, a crise nas crianças; 8) presença de doenças associadas (cardiopatias, úlceras, asma brônquica); 9) uso abusivo de analgésicos; 10) presença de gravidez.

O primeiro aspecto que deve ser analisado, no tratamento medicamentoso, é o uso abusivo de analgésicos pelo enxaquecoso e, às vezes, até mesmo por orientação médica. É comum esse tipo de comportamento, e o fato pode redundar em danos de várias ordens: 1) perpetuação da cefaléia, pelo efeito rebote das drogas (principalmente com o uso de derivados ergóticos, cafeína e, até mesmo, com os analgésicos comuns); 2) efeitos colaterais sérios, em vários setores do organismo (efeitos nefrotóxicos, hepatotóxicos, gástricos, intestinais, na medula óssea, por exemplo); 3) refratariedade ao tratamento profilático pelo "amortecimento" do sistema endógeno de analgesia. Como evitar tais inconvenientes? Pelo uso racional dos medicamentos analgésicos e pela introdução do tratamento profilático nos casos com crises freqüentes.

A nossa orientação, no tratamento com fármacos, é a utilização inicial de um analgésico comum (não narcótico) do tipo Ácido Acetilsalicílico, Paracetamol, Fenacetina ou Ácido Mefenâmico. Outra opção é o uso de antiinflamatórios não esteróides, principalmente o Naproxen Sódico ou o Ibuprofen. O Naproxen, numa dose de $1.100 \mathrm{mg} /$ dia, por períodos de dois a três dias; o Ibuprofen deve ser utilizado com uma dose de ataque de $1200 \mathrm{mg}$ e mantido com $600 \mathrm{mg}$, cada doze horas durante dois a três dias. Respeitar sempre as contra-indicações destas drogas (úlcera péptica em atividade, gastrite erosiva). Sempre associar ao analgésico a Metoclopramida ou Domperidona, drogas que, além de ação antiemética, melhoram a motricidade gástrica (comprometida na crise) e que, por conseqüência, facilitam a absorção dos medicamentos ingeridos por essa via.

Outro recurso, bastante útil e muito empregado, são os derivados ergóticos, introduzidos no tratamento das enxaquecas, há mais de quarenta anos e, portanto, suficientemente testados. A forma mais empregada é o tartarato de ergotamina, que é encontrado, em nosso país, sob várias apresentações: oral, injetável, retal, sublingual e spray nasal (esta última sob a forma de Diidroergotamina). O derivado ergótico deve ser utilizado no início da crise e, se ela persistir por mais de quatro horas, após o início do medicamento, certamente, a ergotamina não será eficaz. A escolha do tipo de apresentação depende dos seguintes fatores: 1) necessidade de ação rápida; 2) presença ou não de náusea e/ou vômito; 3) disponibilidade da preparação no início da crise; 4) preferência do paciente. Geralmente, a ergotamina está associada à cafeína, em virtude da ação sinérgica dessas drogas. Lembrar que um efeito colateral comum da ergotamina é a náusea. A dose dos derivados ergóticos não deve exceder a $6 \mathrm{mg} /$ dia e $12 \mathrm{mg} / \mathrm{semana}$. O uso abusivo dessa droga pode levar ao fenômeno de dependência 
do "ergot", e a sua abstenção determina cefaléia. O consumo exagerado de ergotamina pode determinar sintomas de vasoconstricção, traduzidos por extremidades frias e úmidas. Os ergóticos estão contra-indicados nas doenças vasculares periféricas, angina do peito, hipertensão arterial grave, doença renal ou hepática, gestação, estados infecciosos e devem ser evitados em pacientes idosos.

Outro abortivo de crise, de alguma eficácia, é o isometepteno, que apresenta ação simpaticomimética e vasoconstrictora. Esta droga está disponível, no mercado farmacêutico brasileiro, associada à cafeína e dipirona. Está contra-indicada em pacientes com glaucoma, hipertensão arterial e cardiopatia. Não deve ser utilizada em pacientes que estejam usando inibidores da monoaminoxidase (IMAO).

Nesta década, foi introduzido o Sumatriptan no tratamento da crise de enxaqueca. Este medicamento é um agonista de receptor 5-HT 1D, apresentando uma alta eficácia no controle da crise. É encontrado sob a forma injetável ( $6 \mathrm{mg} / \mathrm{ampola})$ e oral ( 50 e $100 \mathrm{mg} / \mathrm{com}$ primido). O Sumatriptan não exige o uso de antieméticos, porque age também na náusea. Alguns efeitos colaterais têm sido relatados com esta droga: formigamento no tórax e membros, rubor na face, fadiga, sonolência, dor na nuca e sensação de aperto na região precordial.

No estado de mal enxaquecoso (crise intensa que se prolonga por mais de setenta e duas horas), a hospitalização do paciente, às vezes, se impõe pela necessidade de uso de medicamentos injetáveis (vide capítulo VI): Dexametasona por via venosa na dose de $16 \mathrm{mg} / \mathrm{dia}$ ou Acetato de Metilprednisolona na dose de $80 \mathrm{mg} /$ dia, também na veia e sempre com a associação de um antiemético. A Diidroergotamina injetável parece ser eficaz para reverter a situação, entretanto esta forma não está disponível no mercado farmacêutico brasileiro. Também tem sido preconizado, nestes casos, o uso de Clorpromazina. Em nosso serviço, temos utilizado a dose de $0,7 \mathrm{mg} / \mathrm{kg}$, respeitando a dose máxima de $50 \mathrm{mg}$. A droga é administrada em $250 \mathrm{ml}$ de solução fisiológica num prazo de uma hora. Durante este período e por mais sessenta minutos após o término da infusão, o paciente permanece deitado, para se evitar hipotensão ortostática. Os resultados foram ótimos (paciente sem dor ao término da infusão) em mais de $90 \%$ dos casos. A eficácia deste grupo de drogas guarda relação com uma possível hiperatividade dopaminérgica, presente nestes pacientes com enxaqueca.
Os critérios fundamentais para a instituição do tratamento profilático são de três ordens: frequiência, duração e intensidade das crises. Adota-se, como pré-requisito para este tipo de tratamento, a ocorrência de, pelo menos, uma crise/mês, entretanto crises de longa duração (dois a três dias) e de grande intensidade podem justificar um tratamento de manutenção, mesmo que ocorram com menor freqüência. $\mathbf{O}$ tratamento profilático pode requerer medidas diferenciadas para cada tipo de EXQ e para cada paciente em particular. Nós contamos, hoje, com cinco tipos de drogas de primeira linha para este tratamento: bloqueadores dos canais de cálcio (Flunarizina), betabloqueadores (Propranolol, Atenolol e o Nadolol), Maleato de Metisergida, Amitriptilina e Pizotifeno. Embora os bloqueadores dos canais de cálcio constituam uma grande família farmacológica, a Flunarizina é a droga mais eficaz no tratamento da EXQ. É utilizada na dose de 5 a $10 \mathrm{mg} /$ dia, durante pelo menos cento e oitenta dias. O paciente deve ser alertado para o fato de que a droga poderá demorar até trinta dias para iniciar seu efeito benéfico. Os principais efeitos colaterais; são ganho de peso, depressão do humor e sonolência. Os quadros de impregnação do sistema nervoso central, com manifestação parkinsoniana, praticamente não ocorrem com doses baixas e em pacientes jovens. Outros bloqueadores dos canais de cálcio, como a Nimodipina e o Verapamil, são de eficácia duvidosa no tratamento da EXQ.

Os betabloqueadores são também muito eficazes no controle do enxaquecoso e não se conhecem os mecanismos de sua ação. As doses de Propranolol se situam entre 40 e $160 \mathrm{mg} /$ dia (média de $120 \mathrm{mg} / \mathrm{dia}$ ), e a estratégia é iniciar com doses baixas e fazer incrementos periódicos, com monitoramento da pressão arterial sistêmica e da freqüência cardíaca. Alguns efeitos colaterais podem surgir, como fadiga, depressão, bradicardia, hipotensão arterial e broncoespasmos. Essa droga está contra-indicada em asmáticos, cardíacos (insuficiência cardíaca congestiva) e diabéticos. O Atenolol é utilizado na dose de 50 a $100 \mathrm{mg} / \mathrm{dia}$ em duas tomadas diárias, e as doses eficazes do Nadolol são parecidas ao do Propranolol.

Dos antidepressivos do humor, a Amitriptilina é o mais eficaz e as doses úteis se situam entre 50 e $150 \mathrm{mg} / \mathrm{dia}$. Aqui também se deve iniciar com doses baixas e fazer incrementos de modo gradativo. Efeitos colaterais, como secura na boca, taquicardia, ganho de peso, hipotensão ortostática e sonolência, podem ocorrer. 
Dos derivados do "ergot", o Maleato de Metisergida é o medicamento mais eficaz e deve ser usado na dose de 3 a $6 \mathrm{mg} /$ dia. O tratamento deve ser programado para quatro meses, com interrupção de um a dois meses e, se necessário, repetir a medicação por mais quatro meses. Essa estratégia se justifica pelo risco de aparecimento de fibrose retroperitonial, pericárdica ou pleural, quando do uso prolongado da Metisergida. $\mathrm{O}$ Pizotifeno é um derivado ergótico menos eficaz que a Metisergida e as doses variam de 2 a $4 \mathrm{mg} /$ dia. É comum o aparecimento de sonolência e ganho de peso com tal droga.

Outros fármacos poderão ser utilizados no tratamento profilático: Valproato de Sódio, em doses que podem chegar até $1200 \mathrm{mg} / \mathrm{dia}$, em duas ou três tomadas diárias. A Clonidina, Bromoergocriptina e o Naproxen Sódico têm sido preconizados no tratamento da EXQ relacionada ao período menstrual. Nossa primeira opção seria o Naproxen Sódico, utilizado desde cinco dias antes da data provável do início do fluxo até o primeiro ou segundo dia após, quando, geralmente, ocorre o maior pico de incidência.

\section{CEFALÉIA EM SALVAS}

A cefaléia em salvas (CS) foi, por muito tempo, conhecida através de vasta sinonímia: eritroprosopalgia de Bing, neuralgia ciliar, eritromelalgia da cabeça, cefaléia de Horton, cefaléia histamínica, neuralgia petrosa, neuralgia do esfenopalatino, neuralgia vidiana, neuralgia de Sluder e outras tantas. Nos Estados Unidos, esse tipo de cefaléia recebe a denominação de cluster headache que, em nosso país, recebeu a tradução livre de "cefaléia em salvas". A IHS, em 1988, classificou esta cefaléia como mostrado na Tabela III.

Tabela III - Classificação da cefaléia em salvas*

Cefaléia em salvas

- Cefaléia em salvas, de periodicidade indeterminada

- Cefaléia em salvas, episódica

- Cefaléia em salvas, crônica

- Forma crônica, primária

- Forma evoluída de uma forma episódica

- Formas assemelhadas de cefaléia em salvas que não preenchem todos os critérios descritos

*Segundo a International Headache Society
A forma episódica é caracterizada por surtos de dor que desaparecem num prazo de sete dias a um ano, separados por períodos livres de dor superiores a catorze dias. Na forma crônica, as crises ocorrem por período superior a um ano sem que haja remissões ou com remissões menores que catorze dias.

Segundo Kudrow, a CS tem uma prevalência de 0,4 a $1 \%$. Os homens são mais acometidos, numa proporção de 6:1 e os primeiros surtos costumam aparecer entre os vinte e cinqüenta anos de idade.

As crises de dor são de início súbito, atingindo seu pico entre dois e quinze minutos. Sua intensidade é referida como excruciante, sua qualidade, explosiva, sendo, ocasionalmente, de caráter latejante. Em cerca de 10 a $20 \%$ dos pacientes com CS, há relato concomitante de paroxismos de dor na região ocular, de curtíssima duração (segundos) que ocorrem em rápida sucessão ice-pik syndrome. O quadro álgico localiza-se no globo ocular ou ao seu redor, ou, mais raramente, nas têmporas, sendo extremamente raras as localizações na face, pescoço, ouvido ou num hemicrânio. Cerca de $50 \%$ dos pacientes fazem referência a um aumento de sensibilidade na junção occipitocervical, homolateral à dor. As crises ocorrem apenas num lado da cabeça, mesmo em surtos sucessivos, havendo troca de lado somente em 15\% dos casos. A duração das crises é de vinte minutos a duas horas. O número de crises nas vinte e quatro horas, na forma episódica, pode chegar a oito crises/dia (média duas crises/dia). Nas formas crônicas, as crises deixam de ter caráter diário e acontecem duas a três vezes na semana. As crises costumam ocorrer no mesmo horário do dia (o paciente, geralmente, sabe o horário em que vai ter a crise) e pelo menos $50 \%$ dos pacientes têm crises noturnas, que costumam ocorrer, aproximadamente, duas horas após o início do sono, na chamada fase REM. Nas formas episódicas, os períodos de remissão variam de um mês a dois anos. O quadro álgico costuma ser acompanhado de manisfestações autonômicas, bem evidentes no lado acometido. O lacrimejamento é o fenômeno mais freqüente, embora outros devam ser considerados: congestão ocular e nasal, rinorréia, sudorese, palidez na região frontal, discreto edema palpebral. Estas manifestações disautonômicas têm nítido predomínio no lado da dor, embora possam ser observadas bilateralmente. Em cerca de $2 / 3$ dos pacientes, na fase crítica, pode ser observada a síndrome de Horner (miose/ptose palpebral parcial). Embora excepcionalmente, os sálvicos podem referir fotofobia e parestesias nos períodos críticos. É muito comum 
que, nos períodos suscetíveis, tais pacientes tenham as suas crises desencadeadas pela ingestão de bebidas alcoólicas, independentemente da quantidade ingerida. As crises ocorrem, geralmente, cinco a quarenta e cinco minutos após a sua ingestão. Outro fato observado é que boa parte dos sálvicos é grande consumidora de álcool e fumo. Para alguns autores, tal fato contribui para o aparecimento da "facies leonina", presente em alguns pacientes. Outros fatores, de menor importância, também são referidos como possíveis desencadeantes da crise: stress emocional, exposição ao calor ou frio, estados infecciosos e a ingestão de determinados alimentos (chocolate, ovo).

Poucos procedimentos podem ter efeito benéfico para aliviar uma crise. Ekbom refere que a compressão da artéria temporal provoca alívio temporário em cerca de $40 \%$ dos casos; de forma semelhante, a prática de exercícios vigorosos, iniciados concomitantemente com o deflagrar de uma crise, por vezes, tem a capacidade de abortá-la. Casos familiares de CS são descritos na literatura, entretanto com uma incidência muito menor que os relatados para as enxaquecas.

Por vezes, crises assemelhadas às da CS podem vir associadas a outras entidades, como se segue: 1) cefaléia em salvas e neuralgia trigeminal, envolvendo, geralmente, o primeiro ramo do trigêmeo (cluster-tic syndrome); 2) cefaléia em salvas e vertigem, descritas primeiramente por Gilbert, em 1965. Nesta situação, as crises vertiginosas acompanham algumas ou até todas as crises de CS, desaparecendo completamente nos períodos de remissão (cluster-vertigo); 3) cefaléia em salvas e enxaqueca, quando uma crise enxaquecosa pode ser acompanhada de manifestações autonômicas próprias da CS, ou esta pode ser acompanhada de sintomas associados, próprios da enxaqueca (cluster-migraine).

Do ponto de vista fisiopatológico, duas teorias devem ser consideradas. A teoria central, na qual se atribui um papel fundamental ao hipotálamo, cujos núcleos caudais têm a função de modular funções autonômicas, enquanto os núcleos localizados rostralmente agem como moduladores circadianos. Esse "relógio biológico", que explicaria, por exemplo, a periodicidade das crises de CS, é modulado pela serotonina e, talvez, à semelhança com o mecanismo das enxaquecas, possa ocorrer uma instabilidade na função deste neurotransmissor.

A teoria periférica baseia-se em achados, por alguns autores, da ocorrência, durante as crises, de fluxo sangüíneo aumentado na vasculatura extracraniana.
Essas alterações, entretanto, são provavelmente secundárias a descargas neuronais operacionalizadas através do $\mathrm{V}$ nervo (sistema trigêminovascular). A dor, durante as crises, envolve, geralmente, a $1^{\mathrm{a}}$ e $2^{\mathrm{a}}$ divisões do nervo trigêmeo, através dos quais, por condução drômica e antidrômica, seriam liberadas substâncias provocadoras de dor (bradicinina, galanina e substância $\mathrm{P}$, entre outras).

No que tange às alterações bioquímicas, não existem, até o momento, dados que expliquem completamente a patogênese da CS. Assim, discretas elevações nos níveis de serotonina são observadas durante os episódios de dor, em alguns pacientes, bem como aumentos séricos de histamina e de mastócitos. A histamina foi, por longo tempo, envolvida com a CS, porque pacientes com ela apresentam uma maior incidência de úlcera péptica, ou pela capacidade da histamina de desencadear uma crise.

O diagnóstico da CS se impõe pelo quadro clínico, não havendo exames complementares que possam auxiliar na sua comprovação. $O$ uso de alguns fármacos pode reproduzir uma crise de CS, a saber, a histamina, os vasodilatadores coronarianos e, até mesmo, a ingestão de bebidas alcoólicas. A indução de crises de CS só será possível nos períodos suscetíveis. No diagnóstico diferencial, devem ser consideradas doenças: da órbita, neoplásicos do tronco encefálico ou da transição occipitocervical, do seio cavernoso (aneurismas, tromboses), do nervo trigêmeo (particularmente neuralgias).

O tratamento da CS pode ser desdobrado em sintomático (da crise) e profilático (de manutenção). No sintomático, a inalação de oxigênio puro (5 a 7 litros/minuto durante cinco a quinze minutos) pode debelar uma crise rapidamente, em cerca de $70 \%$ dos pacientes. $\mathrm{O}$ tratamento farmacológico poderá ser feito com Tartarato de Ergotamina (particularmente na apresentação sublingual) ou com Diidroergotamina injetável (não disponível no mercado brasileiro). Entretanto, o medicamento mais eficaz no combate à crise é o Sumatriptan (via subcutânea), eficaz em $90 \%$ das vezes.

O tratamento profilático, cujo objetivo é evitar que o paciente tenha crises durante os períodos de surtos, pode ser feito com vários tipos de fármacos. $\mathrm{O}$ mais eficaz é o Verapamil, bloqueador de canal de cálcio, na dose de 80 a $360 \mathrm{mg}$ ao dia (média de $240 \mathrm{mg} / \mathrm{dia}$ ) em duas tomadas. A Flunarizina (outro bloqueador de canal de cálcio) poderá ser utilizada como alternativa (5 a $10 \mathrm{mg} /$ dia), sem a mesma eficácia clínica. 
A Prednisona é também bastante eficaz, na dose de 40 a $60 \mathrm{mg} / \mathrm{dia}$, numa única tomada, pela manhã. O período de administração é de quatro semanas, fazendo-se diminuições progressivas até sua retirada total. É preciso respeitar suas contra-indicações (osteoporose, hipertensão arterial e diabetes).

O Maleato Metisergida, outra opção preventiva, deve ser administrado na dose de 3 a $8 \mathrm{mg} / \mathrm{dia}$, em três tomadas diárias.

O Valproato de Sódio, na dosagem de 600 a $1500 \mathrm{mg} /$ dia, pode ser utilizado, quando as outras medicações não tiverem sucesso.

Na forma crônica, o Verapamil é também a droga de escolha, nas mesmas dosagens preconizadas para tratamento da forma episódica.

O Carbonato de Lítio (600 a $900 \mathrm{mg} / \mathrm{dia}$, com monitorização da litiemia) tem se revelado eficaz no tratamento desta forma de CS.

Outros procedimentos têm sido utilizados, como aplicação de bloqueios anestésicos com lidocaína, capsaícina ou cocaína, através de gotas para instilação nasal. Alguns procedimentos invasivos têm sido indicados nos casos rebeldes às medidas farmacológicas. Dentre tais procedimentos, devem ser considerados os seguintes: injeções de glicerol na cisterna trigeminal; rizotomia trigeminal; neurectomia do nervo petroso superficial e a descompressão do intermédio.

\section{CEFALÉIA DO TIPO TENSIONAL}

A cefaléia do tipo tensional (CTT), comumente denominada de cefaléia de contração muscular ou cefaléia psicogênica, é, ainda, pobremente compreendida e definida de maneira imprecisa. Este tipo de cefaléia é descrito como uma dor ou sensação de aperto, pressão ou constricção, amplamente variáveis na frequiência, intensidade e duração. De duração habitualmente prolongada e, geralmente, de localização suboccipital. Também é comum afirmar-se que essa forma de cefaléia está associada a uma contração prolongada dos músculos esqueléticos do segmento cefálico (cabeça/pescoço), como parte da reação do indivíduo a situações de stress do cotidiano, sem que existam alterações estruturais permanentes.

A partir de 1988, a IHS definiu melhor esse tipo de cefaléia, classificando-a em forma episódica e crônica (Tabela IV).

Cefaléia do tipo tensional episódica - Definida como episódios recorrentes de cefaléia, que preenchem os critérios diagnósticos especificados pela IHS.
Esta forma de cefaléia não apresenta pródromos ou aura. A dor é de caráter contínuo, não pulsátil, referida como pressão ou aperto. Sua intensidade varia de um grau leve a moderado, diferentemente da crise de enxaqueca, cuja variação de intensidade é de moderada a muito intensa. Sua localização é variável, envolvendo as regiões frontal, temporal occipital e parietal, de modo isolado ou combinado, podendo mudar de localização no decorrer de uma crise. Acompanha a crise uma certa sensação de desconforto da região cervical. Apenas 10 a $20 \%$ dos pacientes referem suas crises como sendo unilaterais.

Não está comprovada a associação dessa forma de cefaléia com ansiedade e/ou depressão, ao contrário das enxaquecas, onde tal relação é estreita. A cefaléia tipo tensional (CTT) e as enxaquecas têm sido consideradas como entidades distintas, orientação mantida pela IHS, podendo os pacientes apresentarem formas mistas de cefaléias. Recentemente, alguns autores postulam que a EXQ e a CTT façam parte de um contínuo, com uma mesma fisiopatologia, diferindo apenas nas características clínicas da dor. Nesse sentido, alguns argumentos devem ser alinhados. Ambas as formas de cefaléia são recorrentes, sendo que $62 \%$ dos enxaquecosos relatam sofrer também de CTT e, no decurso do quadro, desenvolvem características enxaquecosas típicas. Por outro lado, sintomas associados ao quadro álgico da EXQ, como: náuseas, vômitos, foto/fonofobia e tontura, raramente aparecem na CTT , talvez porque a presença destas manifestações esteja relacionada à intensidade da dor, que raramente atinge uma intensidade forte neste tipo de cefaléia. Outros argumentos que contribuem para distinguir (ou não) essas duas formas de cefaléia é o fato de

Tabela IV - Classificação da Cefaléia tensional* Cefaléia do tipo tensional.

- Cefaléia do tipo tensional, episódica.

- Cefaléia do tipo tensional, episódica, associada a desordem dos músculos pericranianos.

- Cefaléia do tipo tensional, episódica, não associada a desordem dos músculos pericranianos.

- Cefaléia do Tipo tensional, crônica.

- Cefaléia do tipo tensional, crônica, associada a desordem dos músculos pericranianos.

- Cefaléia do tipo tensional, crônica, não associada a desordem dos músculos pericranianos.

*Segundo a International Headache Society 
ambas responderem a analgésicos comuns, ressaltando-se que a CTT não melhora com o uso de derivados ergóticos ou até pioram. $\mathrm{O}$ exercício físico pode causar certo alívio na intensidade da dor, na CTT, enquanto que agrava sobremaneira a crise de enxaqueca.

Mesmo se levando em conta os elementos alinhados acima, para o diagnóstico diferencial, há casos em que a distinção é bastante difícil. Certamente, as semelhanças entre elas são maiores do que as dessemelhanças. Raskin \& Appenzeller chegam a afirmar que essas modalidades não seriam diferentes, apenas estariam em localizações não superponíveis, dentro de um continuum.

Cefaléia do tipo tensional crônica - Os critérios para se firmar esse tipo de diagnóstico exigem que os pacientes apresentem dor de cabeça no mínimo durante quinze dias por mês e por um período que varia, entre diferentes fontes, de três a seis meses. A maioria, entretanto, chega a referir cefaléia diária ou quase diária. Acredita-se que em tais pacientes coexistam patologias da esfera psicoafetiva (ansiedade ou depressão), ficando difícil se estabelecer uma relação de causa e efeito. Sabe-se, hoje, que a serotonina é um dos principais neurotransmissores envolvidos na depressão, ansiedade e na enxaqueca. Existem trabalhos que demonstram, que os pacientes com CTT apresentam diminuição de serotonina intraplaquetária. É bem possível que as entidades nosológicas, aqui discutidas, às vezes, em situação de comorbidade, tenham uma base biológica comum.

Mecanismo da CTT - Acreditava-se ser essa forma de cefaléia corolário de contração prolongada da musculatura pericraniana, determinada por reação emocional ou pela própria dor. Esta "contração tônica" levaria a uma isquemia tecidual e à dor conseqüente. Entretanto, estudos posteriores evidenciaram que os pacientes enxaquecosos apresentam alterações na musculatura pericraniana, durante uma crise, em nível proporcionalmente mais elevado que o daqueles com CTT. Medidas do fluxo sangüíneo muscular, na vigência da CTT, se mostraram absolutamente normais, o que abalou seriamente o conceito de isquemia muscular como fator gerador de dor nesse tipo de cefaléia. A Tabela V aponta evidências de mecanismos fisiopatológicos comuns entre as enxaquecas e as CTT.

Acredita-se que a dor crônica dependa de uma solicitação mecânica excessiva da membrana miofacial, que envolve os músculos. Na região em que ocorre a contração, a membrana liberaria certas substâncias químicas, como radicais ácidos, que irritam as terminações nervosas, livres, e induziriam o aparecimento de dor. Olesen et al. propõem um modelo vasculomiogênico supra-espinhal para os pacientes com EXQ e CTT. Nesse modelo, o nucleo caudalis (parte do complexo trigeminal), que recebe influxos nociceptivos dos vasos sanguíneos encefálicos e da musculatura pericraniana, exerceria um papel relevante. Tanto na EXQ como na CTT podem ocorrer impulsos facilitadores supra-espinhais com ativação dos nociceptores do nucleo caudalis. Nos pacientes com enxaqueca, o nociceptor vascular está hipersensível, enquanto, nos pacientes com CTT, o nociceptor miofacial seria o hiperativo. Ficariam, assim, explicadas as variações nas expressões clínicas das duas vertentes (vascular e muscular), predominando a estimulação vascular na EXQ e a miofacial na CTT.

Tabela $V$ - Mecanismos patogênicos comuns às enxaquecas e às cefaléias tensionais

- Aumento de sensibilidade na musculatura pericraniana;

- Achados eletromiográficos anormais;

- Diminuição da serotonina plaquetária;

- Concentrações reduzidas de betaendorfinas de líquido cefalorraqueano.

\subsection{Tratamento da CTT}

O enfoque terapêutico deste tipo de cefaléia também pode ser desdobrado em sintomático e profilático. O tratamento sintomático, principalmente nas formas episódicas, deve ser orientado com analgésicos comuns ou com antiinflamatórios não esteróides. Às vezes, o emprego de benzodiazepínicos (com a finalidade de relaxamento muscular), por curto período, poderá ser útil. Procedimentos não medicamentosos podem ser empregados, com o objetivo de diminuir o grau de tensão muscular: massagens suaves na musculatura cervical, aplicação de calor úmido local, banhos quentes de imersão, exercícios de ioga, meditação transcendental e outras técnicas de relaxamento. Uma das técnicas utilizadas com esta finalidade, é o aprendizado do relaxamento com o aparelho de bio-feedback. Algumas técnicas de medicinas alternativas têm sido preconizadas: acupuntura, do-in, acupressura. 
O tratamento profilático começa com a abordagem do paciente, na primeira consulta, através de um esclarecimento do seu tipo de problema. É importante que o terapeuta indague o tipo de ocupação do paciente, pois a cefaléia pode estar relacionada com o tipo de ocupação desta pessoa, como é o caso da datilógrafa, do dentista, do digitador, que trabalham por horas seguidas numa mesma postura. Também é importante saber como o paciente lida com seus problemas do dia-a-dia.

No tratamento farmacológico são empregadas as mesmas drogas utilizadas no preventivo das enxaquecas.

\section{CEFALÉIA CRÔNICA DIÁRIA}

Dos pacientes que procuram tratamento médico para suas dores de cabeça, cerca de 35 a $40 \%$ têm cefaléia com uma freqüência quase que diária. Apesar de a cefaléia crônica diária não estar incluída na classificação da IHS, existe um consenso sobre sua caracterização clínica. São pacientes que iniciam sua história de crises de enxaqueca, com ou sem aura, ao redor dos 20 anos de idade, e que, progressivamente, vão se tornando mais frequientes. O paciente passa, então, a referir um padrão de cefaléia tipo tensional, de caráter diário ou quase diário, associado a episódios de dor, com características e comemorativos das enxaquecas. Da população de pacientes com cefaléia crônica diária (CCD), cerca de $20 \%$ são considerados como primários (crises diárias desde o início), enquanto a maioria (80\%) advém de um quadro de enxaqueca transformada (ET). Esta entidade (ET) foi primeiramente descrita por Mathew et al., em 1987. Alguns fatores podem predispor o seu aparecimento, como: consumo abusivo de analgésicos (presente em cerca de 80\% dos pacientes); alterações psicoafetivas (depressão e ansiedade); situações traumáticas da vida; hipertensão, reposição hormonal feminina; "stress", entre outros. Nas mulheres, as crises do tipo enxaqueca estão geralmente relacionadas ao período perimenstrual. Algumas comorbidades estão relacionadas a esta entidade: quadros de hipertensão intracraniana benigna e a apnéia do sono. As mais importantes, entretanto, se referem às alterações do humor, como a depressão e a ansiedade. Além do fato de que esses pacientes estariam mais sujeitos à prática de uso abusivo de drogas ilícitas, alto consumo de nicotina (grandes tabagistas) e tendência suicida.

Dois fatores parecem ter grande influência no prognóstico desses pacientes. O uso abusivo de analgésicos e a presença de comorbidades. Os pacientes com uso abusivo de analgésicos (consumo de analgésicos ou ergotamina mais de três vezes por semana), deverão, obrigatoriamente, se abster de seu uso, condição para a obtenção de resposta clínica ao tratamento profilático a ser proposto. Os pacientes deverão ser informados de que, nesta fase, poderá ocorrer uma piora temporária na intensidade de suas crises (cefaléia rebote). Cerca de $20 \%$ dos pacientes têm seu quadro melhorado pelo simples fato de interromperem a utilização das drogas analgésicas. Nesta fase, somos da opinião de que os doentes devam ser tratados com antiinflamatórios não hormonais, utilizados diariamente, desde que não existam contra-indicações. As drogas mais utilizadas são o Naproxeno e o Ibuprofeno, com preferência para o primeiro, por sua maior eficácia. Tais drogas devem ser utilizadas diariamente, por duas semanas. Concomitante à utilização destas drogas, inicia-se o tratamento com drogas profiláticas. São utilizados os antidepressivos tricíclicos (preferencialmente a Amitriptilina), os betabloqueadores, o Valproato de Sódio, nas mesmas doses preconizadas para o tratamento das enxaquecas. A estas medicações podem ser associadas medicações específicas no tratamento das comorbidades, quando existirem. O seguimento longitudinal mostra que $31 \%$ desses pacientes pouco alteram a história de suas crises, a despeito dos tratamentos propostos, farmacológicos ou comportamentais.

SANVITO WL \& MONZILLO PH. Primary headaches: clinical and therapeutic aspects. Medicina, Ribeirão Preto, 30: 437-448, oct./dec. 1997

ABSTRACT: In this review, primary headaches are defined as chronic diseases of episodic or continuous clinical presentation and unknown etiology, but of dysfunctional, not structural nature. The four main categories of primary headache (migraine, cluster headache, stress headache or chronic daily headache) are discussed in their etiopathogenic, clinical and therapeutic aspects.

UNITERMS: Headache. Therapeutics. 


\section{BIBLIOGRAFIA RECOMENDADA}

1 - EDMEADS J. Headache in the emergency departament. Headache. 4 th ed, Sandoz, Basel, 1992.

2 - EVANS RW. Diagnostic testing for the evaluation of headaches. Neurol Clin 14: 1-26, 1996.

3 - FARIAS DA SILVA W. Cefaléias: diagnóstico e tratamento. Editora Médica e Clínica, Rio de Janeiro, 1989.

4 - MATHEW NT. Advances in cluster headache. Neurol Clin 8: 867-890, 1990.

5 - HEADACHE CLASSIFICATION COMMITTEE OF THE INTERNATIONAL HEADACHE SOCIETY. Classification and diagnostic criteria for headache disorders, cranial neuralgias and facial pain. Cephalalgia 8: 1-96, 1988. Suppl. 7.
6 - RAFFAELLI JR E \& MENON AD. O que você deve saber sobre cefaléia. Associação Paulista de Medicina, São Paulo, 1992.

7 - RASKIN NH. Acute and prophylatic treatment of migraine. Neurology 3: S39-S42, 1993. Suppl. 3.

8 - SANVITO WL. Cefaléias primárias. Rev Bras Med 53: 27-35, 1996.

9 - SAPER JR et al. Handbook of headache management. Williams \& Wilkins, Baltimore, 1993.

Recebido para publicação em 05/11/97

Aprovado para publicação em 10/12/97 